DOI: $\underline{10.20472 / T E .2016 .4 .1 .003 ~}$

\title{
ADAPTATION OF THE ACADEMIC COPING STRATEGIES SCALE IN TURKEY: A STUDY WITH UNDERGRADUATES*
}

\author{
BERKE KIRIKKANAT, MAKBULE KALI SOYER
}

\begin{abstract}
:
The Academic Coping Strategies Scale (the ACS Scale) developed by Sullivan in 2010 is a pivotal screening tool for counselors and educators to understand undergraduates' handling mechanisms in a tough academic context. This study presents the psychometric features of Turkish version of the scale. 555 undergraduates from three universities in Istanbul participated in the study. Exploratory and confirmatory factor analyses advocated a three factor solution like the original scale. Criterion validity was examined through the variables - academic self-efficacy, and learning, performance-approach and performance-avoidance goal tendencies-. The results indicated academic coping strategies had significant correlations with them. Test-retest study yielded consistent scores. These findings point that the Turkish ACS Scale is a credible measurement providing great opportunities for scrutinizing undergraduates' coping patterns utilized for a demanding educational context.
\end{abstract}

\section{Keywords:}

Academic Coping Strategies Scale, adaptation, undergraduates

JEL Classification: 120, 123, 129

\section{Authors:}

BERKE KIRIKKANAT, Istanbul Commerce University, Turkey, Email: bkirikkanat@ticaret.edu.tr MAKBULE KALI SOYER, Marmara University, Turkey, Email: makbulesoyer@marmara.edu.tr

\section{Citation:}

BERKE KIRIKKANAT, MAKBULE KALI SOYER (2016). Adaptation of The Academic Coping Strategies Scale in Turkey: A Study With Undergraduates*. International Journal of Teaching and Education, Vol. IV(1), pp. 26-44., 10.20472/TE.2016.4.1.003

*The present study was conducted as a part of the PhD dissertation named 'A Path Analysis Model Pertinent to Undergraduates' Academic Success: Examining Academic Confidence, Psychological Capital and Academic Coping Factors' by Berke Kırıkkanat whose PhD advisor was Assistant Professor Makbule Kalı Soyer. 


\section{Introduction}

Encountering tough, challenging situations in every area of life is in all likelihood. When individuals experience such a circumstance, a prevalent psychological state is possible to come out. It is depicted as stress, the product of interplay between a person and a demanding environment, which causes him to think he cannot deal with this arduous condition through his current capacities (Lazarus and Folkman, 1984). Especially, it is quite common among university students who face precipitous changes ranging from accommodation, life standards to academic and amical burdens (Lowe and Cook, 2003). It is even higher in degrees for undergraduates than the other members of the society (Adlaf, Gliksman, Demers and Newton-Taylor, 2001). Thus, coping mechanisms are considered as significant concerns for counselors, mental health professionals and educational policy makers who would like to optimize students' mood via facilitating constructive pathways to solve their problems, and by considering stress as a crucial factor shaping their success (Bataineh, 2013).

For Lazarus and Folkman (1984), coping refers to 'constantly changing cognitive and behavioral efforts to manage specific external and/or internal demands that are appraised as taxing or exceeding the resources of the person' (p.178). According to them, coping does not contain fixed plans of actions, thoughts or emotions which reflect the aspect of personality characteristics. Instead, it encompasses continuous alterations in cognitive, behavioral or affective manners in respect to the variations in the synergy between the individual and stringent context. Therefore, the one can either rely on problem-focused coping or emotion-focused coping depending on this interaction. Problem-focused coping includes direct actions changing the trouble at hand in the setting leading to the feeling of stress. Emotion-focused coping, on the other hand, indicates the deed of adjusting affective behaviors disclosed when dealing with the conflict in the case. In this regard, coping strategies utilized by college students when they have difficulty in coming to a conclusion in their social, academic or emotional challenges during their training are revealed as pivotal issues which should be investigated profoundly (Sullivan, 2010).

Preceding studies did not emphasize the types of stressors university students had to deal with in their higher education. They largely focused on how pupils reacted to a prevailing occurrence edging on their limits in daily life (Sullivan, 2010). According to Sullivan, college students utilize diverse coping strategies in respect to the kind of their problem. When they feel overloaded due to the requirements as well as the responsibilities they must fulfill so as to be successful at their majors, they go through academic stress. It can be interpreted as their mental view of lacking sufficient dealing mechanisms necessary for academic appeals in university context. For example, a student must be able to comply with due dates for course works, projects, examinations, presentations etc. and organize his social life resting upon these dates. He must have the ability to bear hardships during the completion of his training, and to find his way out in order to get adequate scholastic achievement (Ben-Zur and Zeidner, 2012). Yet, when he does not possess these coping skills, academic stress arises. As a result, proper means of coping become an important tool for undergraduates who would like to self-regulate their learning and to gain autonomy over their educational processes (Lawrence, Ashford and Dent, 2006).

For Struthers, Perry and Menec (2000), college students apply peculiar coping systems to tedious educational settings. These coping mechanisms are distinctive approaches from familiar dealing 
tendencies. They encompass idiosyncratic arrangements of affections and conducts in regard to tense academic contexts. They are labelled as academic coping strategies (Thien and Razak, 2013). From the view of Sullivan (2010), these strategies are less recognized and investigated as opposed to common handling mechanisms. For him, examining the systems used in dealing with academic stressors is very essential to grasp the reasons underlying academic failures of undergraduates and to give them critical advice so as to improve their educational growth.

To figure out undergraduates' coping strategies utilized in a typical academic challenge, Sullivan (2010) engendered the Academic Coping Strategies Scale (the ACS Scale). It identifies students' coping mechanisms which are employed in response to a failure in an examination, making them ponder on what they would do in such a condition. For educators and counselors, the ACS Scale provides a great opportunity to understand which teaching intervention and career counseling practice would work best for undergraduates who could not reach the desired level of achievement in their university education. For college students, it is served as an efficacious measurement screening their coping strategies in a usual educational problem, which in turn gives them a chance to express their individual differences in solving the same struggle. Such a comprehension makes students perceive themselves as unique human beings having different needs and supports in dealing with a particular academic stress.

Researches in which the ACS Scale was applied indicate that it contributes to good consequences regarding the comprehension of undergraduates' academic coping strategies. For instance, Hsieh, Sullivan, Sass and Guerra (2012) conducted a study whose aim was to assess hypothetical models suggesting psychological variables forecasted undergraduates' academic achievement. The variables contained personal control, self-efficacy, mastery goal orientation, academic coping strategies and self-regulation. Results showed that all of these factors had a great influence on the formation of scholastic accomplishments. Specifically, academic coping strategies built significant correlations with self-efficacy, mastery goal tendency and selfregulation, which in turn results in qualified attainments of college students. In addition, Kuncharin and Mohamad (2014) scrutinized the impact of academic coping strategies on Thai college students' success. Results demonstrated that the most effective coping strategy in forming academic achievement for Thai students was social support, reflecting their collectivistic structure of the community.

Consequently, the ACS Scale displays an outstanding information resource for the experts at the area of counseling, educational psychology and psychiatry to discern undergraduates' dealing mechanisms applied in the academic atmosphere. The scale lets us inspect why some students attain good grades while others cannot get enough marks to pass the level of education they are part of. It assists the progress of forming initial interventions necessary for the pupils having lots of scholastic failures. By its favoring the identification of their coping strategies, it allows them to be aware of their inadequate reactions to academic stress, and helps them revise their conducts accordingly. Hence, the objective of the present research was to adapt the ACS Scale developed by Sullivan (2010) to Turkish and to probe its validity and reliability aspects. 


\section{Method}

\subsection{Design}

The study was set up on the basis of descriptive survey research design which emphasizes accumulating information about a specified subject from a considerable number of individuals at a peculiar time (Lodico, Spaulding and Voegtle, 2010). It was founded through cross-sectional study design whose goal was to obtain data at a singular occasion from a representative group of people at distinctive ages, academic degrees, socio-economic status and so on (Cohen, Manion and Morrison, 2007).

\subsection{Participants}

The participants were included in the study via convenience sampling technique which involves picking up the ones who are approachable and amenable at the time of present research. The assembling process is perpetual until the sample reaches its intended amplitude (Cohen et. al., 2007). In the language equivalence study, 50 undergraduates (24 females, 26 males) in the year of freshmen $(n=12)$, sophomore $(n=13)$, junior $(n=11)$ and senior $(n=14)$ in the departments of Electrical-Electronical, Mechatronic and Jewelry Engineering in Istanbul Commerce University were joined. For the validity study, 505 Turkish undergraduates from Istanbul Commerce University ( $n=261)$, Marmara University and Yildiz Technical University $(n=244)$ were attended. It was consisted of 301 female $(59.6 \%)$ and 204 male (40.4\%) pupils. Their age varied from 19 to 25. This sample was composed of 145 freshmen (28.7\%), 101 sophomore (20\%), 143 junior $(28.3 \%)$ and 116 senior (23\%) college students. Moreover, 40 undergraduates (16 females, 24 males) of the validity sample were randomly selected to be part of the test-retest study, operated within the interval of two weeks. It contained pupils in the year of freshmen $(n=19)$, sophomore $(n=7)$, junior $(n=8)$ and senior $(n=6)$ in the department of Law and Management.

\subsection{Materials}

In the present research, there were three tools of measurement: The Academic Coping Strategies Scale, the Academic Self-Efficacy Scale and the Achievement Goal Orientations Scale.

\subsubsection{The Academic Coping Strategies Scale (the ACS Scale):}

The Academic Coping Strategies Scale (the ACS Scale) developed by Sullivan (2010) was applied to Turkish undergraduates in order to conduct its adaptation. It was consisted of 34 items with a three-factor structure labelled as Approach, Avoidance and Social Support on a 5-point scale varying from never to almost always. It started with a hint question called 'Think about a time when you received a low grade on an important exam, significantly lower than what you usually get.' The pupils replied to the scale regarding this clue.

The subscales of the ACS Scale pondered which academic coping strategy was adopted by the college student in dealing with this circumstance mentioned above. Approach subscale measured the one's tendency to make diverse efforts in reaching a conclusion of the presented problem. It assessed one's inclination to do assertive deeds about resolving the challenge. Avoidance 
subscale tested the predisposition of eluding from the trouble situation. It examined the potential shunning behaviors done in this issue, without any actual solution. Social Support subscale investigated whether the individual preferred others' assistance in handling with this difficult condition or not. It inspected his actions of longing for others' aid in coping with the problem (Sullivan, 2010).

Moreover, Approach, Avoidance and Social Support subscales had adequate values for the internal consistency. Cronbach's alpha coefficients for each subscale were summarized as .91, .82 and .82 respectively. Besides, the subscales had significant correlations with some variables such as academic self-efficacy, achievement goal orientation, self-regulation, test anxiety and so on (Sullivan, 2010).

\subsubsection{The Academic Self-Efficacy Scale (the ASE Scale):}

The Academic Self-Efficacy Scale (the ASE Scale) engendered by Jerusalem and Schwazer in 1981 and adapted by Yilmaz, Gürcay and Ekici (2007) to Turkish was administered to the participants in the study. Its objective was to pinpoint college students' faiths about whether they had the ability to accomplish a scholastic duty well or not. Thus, the scale was a significant tool for screening university students' assurance in themselves with respect to their academic skills.

The adapted version of the scale was investigated by Yilmaz, Gürcay and Ekici (2007) with 672 Turkish undergraduates from Gazi University, Ankara University and Hacettepe University. The analysis showed that the scale was composed of 7 items with one factor solution on a 4- point scale. Only one item was reversely coded. Total score demonstrated one's degree of academicself efficacy. The internal consistency coefficient for the scale was .79.

\subsubsection{The Achievement Goal Orientations Scale (the AGO Scale):}

The Achievement Goal Orientations Scale (the AGO Scale) formed by Midgley, Kaplan, Middleton, Maehr, Urdan and Hicks-Anderman (1998) and adapted by Akın and Cetin (2007) to Turkish was used in the present research. The scale tested the underlying mechanisms employed in the successful conduct. It analyzed undergraduates' achievement goal tendencies which had a great impact on their success outcome.

Akın and Cetin (2007) studied the adapted version of the AGO Scale with 607 college students from Sakarya University. Their inquiry indicated that the scale encompassed 17 items with a three factor solution - Learning, Performance-Approach and Performance-Avoidance goal orientations on a 5-point scale. Learning goal tendency entailed the acts of aspiring to acquire knowledge and improve the skills necessary for the duty at hand. Performance-Approach goal inclination involved the behaviors of obtaining benign appraisals of proficiency and surpassing the other individuals in this way. Performance-Avoidance goal predisposition embraced the manners of averting from others' hostile opinions about one's capabilities (Elliot and Harackiewicz, 1996). Cronbach's alpha values for each subscale were $.77, .79$ and .78 ; and their test-retest reliability coefficients were $.95, .91$ and .94 respectively. 


\subsection{Procedure}

Firstly, the three professionals who became expert at the major of counseling and educational psychology in English curriculum translated the original 34-item ACS Scale to Turkish. Then, two of them integrated the translated forms of the scale and developed its final document. Four experts at English language, who had been educated in the area of translation and linguistics back-translated the Turkish form. Two of them worked on optimizing these conversions. They made a decision about the fact that the Turkish and English translations of the scale were compatible with each other. At last, a professional in the field of Turkish Language and Literature examined the Turkish translation in respect to wording as well as grammatical framework, which results in the ultimate version of the Turkish document.

After that, 50 undergraduates (19 to 25 aged) who had been training in English in the departments of Electrical-Electronical, Mechatronic and Jewelry Engineering in Istanbul Commerce University in the year of either freshmen or senior were involved in the language equivalence study. In this research, Turkish and English versions of the ACS Scale were administered within the interval of two weeks.

When the ratification of the language equivalence between the two versions was obtained, the Turkish form of the ACS Scale was applied to 505 undergraduates from Istanbul Commerce University, Marmara University and Yildiz Technical University for the validity analysis. To find out the criterion validity of the scale, the pupils were stipulated to reply the Turkish versions of the ASE Scale and the AGO Scale. Besides, 40 students of the validity sample were randomly chosen for the test-retest study.

\subsection{Method of Analysis}

In the study, exploratory and confirmatory factor analyses were conducted through SPSS 22 and LISREL 8.80 in order to identify the validity of the Turkish version of the ACS Scale. As Sullivan (2010) states that the potential factors would not be pertaining to each other, varimax rotation was utilized in the exploratory factor analysis. The goodness-of-fit indexes operated in the confirmatory factor analysis were $X^{2} / \mathrm{df}$ (chi square / degree of freedom), GFI (Goodness of Fit Index), CFI (Comparative Fit Index), SRMR (Standardized Root Mean Square Residuals) and RMSEA (Root Mean Square Error of Approximation). To test the criterion validity, Pearson correlation coefficient was computed. In addition, Cronbach's alpha and split half reliability coefficients, corrected item total correlation, Pearson correlation coefficients, paired sampled ttest and differences of item means of the upper $27 \%$ and lower $27 \%$ groups in the subscales were gauged to disclose the reliability of the Turkish ACS Scale.

\section{Results}

This section contains five parts stated as outcomes of language equivalence study, exploratory factor analysis, confirmatory factor analysis, criterion validity and reliability analysis. 


\subsection{Findings of Language Equivalence Study:}

The findings of language equivalence study were presented precisely in Table 1. As it is shown, items in Turkish and English version of the ACS Scale did not differ from each other significantly $(p>05)$

Table.1. Results of Paired Sampled $t$-Test in Language Equivalence Study

\begin{tabular}{|c|c|c|c|c|c|c|c|c|}
\hline \multirow{2}{*}{$\begin{array}{l}\text { Paired } \\
\text { Items }\end{array}$} & & \multirow{2}{*}{$N$} & \multirow{2}{*}{$\bar{X}$} & \multirow{2}{*}{$S d$} & \multirow{2}{*}{ SEM } & \multicolumn{3}{|c|}{$t$ Test } \\
\hline & & & & & & $t$ & $d f$ & $p$ \\
\hline \multirow{2}{*}{ Item 1} & Turkish & 50 & 3.30 & 1.09 & .15 & \multirow{2}{*}{-1.17} & \multirow{2}{*}{49} & \multirow{2}{*}{.10} \\
\hline & English & 50 & 3.50 & 1.13 & .16 & & & \\
\hline \multirow{2}{*}{ Item 2} & Turkish & 50 & 2.60 & 1.05 & .15 & \multirow{2}{*}{-.55} & \multirow{2}{*}{49} & \multirow{2}{*}{.58} \\
\hline & English & 50 & 2.66 & 1.12 & .16 & & & \\
\hline \multirow{2}{*}{ Item 3} & Turkish & 50 & 3.40 & 1.03 & .15 & \multirow{2}{*}{.27} & \multirow{2}{*}{49} & \multirow{2}{*}{.79} \\
\hline & English & 50 & 3.36 & 1.14 & .16 & & & \\
\hline \multirow{2}{*}{ Item 4} & Turkish & 50 & 3.42 & 1.11 & .16 & \multirow{2}{*}{-.29} & \multirow{2}{*}{49} & \multirow{2}{*}{.78} \\
\hline & English & 50 & 3.46 & 1.26 & .18 & & & \\
\hline \multirow{2}{*}{ Item 5} & Turkish & 50 & 3.88 & 1.06 & .15 & \multirow{2}{*}{1.11} & \multirow{2}{*}{49} & \multirow{2}{*}{.27} \\
\hline & English & 50 & 3.72 & .99 & .14 & & & \\
\hline \multirow{2}{*}{ Item 6} & Turkish & 50 & 4.12 & .82 & .12 & \multirow{2}{*}{1.55} & \multirow{2}{*}{49} & 12 \\
\hline & English & 50 & 3.98 & .79 & .11 & & & .13 \\
\hline Item 7 & Turkish & 50 & 3.86 & .88 & .12 & 163 & 19 & 11 \\
\hline TEIII & English & 50 & 3.64 & 1.00 & .14 & 1.00 & 45 & .11 \\
\hline Item 8 & Turkish & 50 & 4.16 & .95 & .13 & -23 & 49 & 82 \\
\hline & English & 50 & 4.18 & .77 & .11 & & & \\
\hline Item 9 & Turkish & 50 & 2.84 & 1.09 & .15 & $-1 \cap 0$ & 49 & 32 \\
\hline S & English & 50 & 2.92 & .99 & .14 & -1.00 & 49 & $.0<$ \\
\hline Item 10 & Turkish & 50 & 2.08 & 1.05 & .15 & -24 & 49 & 81 \\
\hline & English & 50 & 2.10 & .97 & .14 & & & \\
\hline & Turkish & 50 & 3.06 & .82 & .11 & -40 & 49 & 69 \\
\hline Item 11 & English & 50 & 3.10 & 1.13 & .16 & & & .09 \\
\hline Item 12 & Turkish & 50 & 3.18 & .87 & .12 & -160 & 49 & 12 \\
\hline Item 12 & English & 50 & 3.34 & 1.13 & .16 & -1.00 & & \\
\hline Item 13 & Turkish & 50 & 3.64 & .87 & .12 & 1.88 & 49 & 07 \\
\hline & English & 50 & 3.34 & 1.20 & .17 & & & \\
\hline & Turkish & 50 & 3.82 & .72 & .10 & & & \\
\hline Item 15 & English & 50 & 3.98 & .71 & .10 & $-1 . / 4$ & 49 & .09 \\
\hline & Turkish & 50 & 3.94 & .77 & .11 & & & \\
\hline Item 15 & English & 50 & 3.68 & 1.02 & .14 & 1.79 & 49 & .08 \\
\hline
\end{tabular}




\begin{tabular}{|c|c|c|c|c|c|c|c|c|}
\hline \multirow{2}{*}{ Item 16} & Turkish & 50 & 2.22 & 1.01 & .14 & \multirow{2}{*}{-.94} & \multirow{2}{*}{49} & \multirow{2}{*}{.35} \\
\hline & English & 50 & 2.30 & .93 & .13 & & & \\
\hline \multirow{2}{*}{ Item 17} & Turkish & 50 & 3.80 & .83 & .12 & \multirow{2}{*}{1.29} & \multirow{2}{*}{49} & \multirow{2}{*}{.20} \\
\hline & English & 50 & 3.62 & .97 & .14 & & & \\
\hline \multirow{2}{*}{ Item 18} & Turkish & 50 & 3.92 & .78 & .11 & \multirow{2}{*}{-.78} & \multirow{2}{*}{49} & \multirow{2}{*}{.44} \\
\hline & English & 50 & 4.00 & .86 & .12 & & & \\
\hline \multirow{2}{*}{ Item 19} & Turkish & 50 & 3.38 & 1.05 & .15 & \multirow{2}{*}{-1.86} & \multirow{2}{*}{49} & \multirow{2}{*}{.07} \\
\hline & English & 50 & 3.64 & 1.02 & .14 & & & \\
\hline \multirow{2}{*}{ Item 20} & Turkish & 50 & 3.34 & .77 & .11 & \multirow{2}{*}{-.93} & \multirow{2}{*}{49} & \multirow{2}{*}{.36} \\
\hline & English & 50 & 3.48 & .97 & .14 & & & \\
\hline \multirow{2}{*}{ Item 21} & Turkish & 50 & 1.98 & .91 & .13 & \multirow{2}{*}{-1.77} & \multirow{2}{*}{49} & \multirow{2}{*}{.08} \\
\hline & English & 50 & 2.04 & .97 & .14 & & & \\
\hline \multirow{2}{*}{ Item 22} & Turkish & 50 & 1.88 & 1.06 & .15 & \multirow{2}{*}{-1.53} & 49 & 13 \\
\hline & English & 50 & 1.98 & 1.00 & .14 & & & \\
\hline & Turkish & 50 & 3.76 & .80 & .11 & -86 & 49 & 39 \\
\hline Item 23 & English & 50 & 3.88 & .98 & .14 & -.00 & 45 & .09 \\
\hline Item 24 & Turkish & 50 & 1.86 & 1.09 & .15 & -1.42 & 49 & 16 \\
\hline Ment 24 & English & 50 & 1.98 & 1.00 & .14 & $1.7 \mathrm{TL}$ & 蒋 & \\
\hline Item 25 & Turkish & 50 & 3.64 & .75 & .10 & .62 & 49 & .54 \\
\hline & English & 50 & 3.58 & .61 & .09 & & & \\
\hline Item 26 & Turkish & 50 & 3.46 & .81 & .11 & -.25 & 49 & 80 \\
\hline nem $<0$ & English & 50 & 3.50 & 1.16 & .16 &.$<v$ & 40 & .00 \\
\hline Item 27 & Turkish & 50 & 2.26 & 1.21 & .17 & -.77 & 49 & .44 \\
\hline & English & 50 & 2.32 & 1.10 & .15 & & & \\
\hline Item 28 & Turkish & 50 & 2.30 & 1.03 & .15 & -1.63 & 49 & .11 \\
\hline & English & 50 & 2.42 & 1.13 & .16 & & & \\
\hline Item 29 & Turkish & 50 & 3.24 & .94 & .13 & -.54 & 49 & .60 \\
\hline & English & 50 & 3.32 & 1.28 & .18 & & & \\
\hline Item 30 & Turkish & 50 & 3.60 & .70 & .10 & -.55 & 49 & .58 \\
\hline & English & 50 & 3.68 & 1.06 & .15 & & & \\
\hline Item 31 & Turkish & 50 & 3.68 & .82 & .11 & 1.60 & 49 & 12 \\
\hline & English & 50 & 3.50 & .89 & .12 & 1.00 & & \\
\hline Item 32 & Turkish & 50 & 2.60 & 1.18 & .17 & -1.40 & 49 & .17 \\
\hline & English & 50 & 2.70 & 1.16 & .16 & & & \\
\hline Item 33 & Turkish & 50 & 3.20 & 1.09 & .15 & -.88 & 49 & 38 \\
\hline & English & 50 & 3.34 & 1.20 & .17 & & & .00 \\
\hline Item 34 & Turkish & 50 & 2.12 & 1.27 & .18 & -1.43 & 49 & .16 \\
\hline & English & 50 & 2.16 & 1.27 & .18 & & & \\
\hline
\end{tabular}




\subsection{Findings of Exploratory Factor Analysis}

In the beginning of exploratory factor analysis (EFA), the items in Turkish ACS Scale were examined based on whether they fulfill the assumptions of factorability or not. Kaiser-Mayer-Olkin (KMO) value was .89, which was above the approved value for sampling (Tabachnick and Fidell, 2007). Barlett's test of sphericity was significant $\left(\chi^{2}(561)=6263.147, p<.001\right)$. It indicated that the correlation matrix unearthed was not equal to the identity matrix. It led to the idea that the data had enough correlations for factorability. Besides, the communalities of the items were higher than the accustomed value of .10 (Tabachnick and Fidell, 2007). Depending on these findings, the 34-item Turkish scale was investigated via the principal component analysis (PCA).

Based on this analysis, the initial Eigen values reflected three factor structure explaining $41 \%$ of the total variance. As Sullivan (2010) mentions that the factors would not be pertinent to one another, a varimax rotation technique was chosen to discern which items were taken part of which factors (Tabachnick and Fidell, 2007).

Table 2 displays the items' dispersion including their factor loadings in rotated component matrix. As it is revealed, the item 19 is not involved in any factor, which forms the thought that the item does not have any relationship with this factor structure. Such an item results in the fact it is irrelevant to the factor solution of the scale (Tabachnick and Fidell, 2007). Hence, it was eradicated from the factor analysis.

Table 2. The Items' Dispersion Including Their Factor Loadings in Rotated Component Matrix

\begin{tabular}{lcc}
\hline \multirow{2}{*}{ Items } & \multicolumn{2}{c}{ Factors } \\
\cline { 2 - 3 } & 1 & 2 \\
\hline Item 17 & .695 & \\
Item 30 & .688 & \\
Item 29 & .684 & \\
Item 14 & .680 & \\
Item 26 & .673 & \\
Item 15 & .651 & \\
Item 13 & .642 & \\
Item 23 & .636 & \\
Item 6 & .616 & \\
Item 25 & .599 & \\
Item 18 & .579 & \\
Item 31 & .573 & \\
Item 7 & .557 & \\
Item 5 & .541 & \\
Item 8 & .393 & \\
Item 12 & .376
\end{tabular}




\begin{tabular}{lll} 
Item 20 & .794 & \\
Item 3 & .747 & \\
Item 4 & .745 & \\
Item 33 & .742 & \\
Item 1 & .735 & \\
Item 11 & .683 & \\
Item 32 & .407 & \\
Item 22 & .366 & \\
Item 10 & & .726 \\
Item 21 & & .702 \\
Item 24 & & .671 \\
Item 28 & & .644 \\
Item 34 & & .585 \\
Item 27 & & .585 \\
Item 16 & & .471 \\
Item 9 & & .465 \\
Item 2 & & .464 \\
Item 19 & & \\
\hline
\end{tabular}

Subsequently, remaining 33 items were scrutinized via the principal component analysis with a varimax rotation. It produced a three factor solution explaining $42 \%$ of total variance. In Table 3 , the eventual factor structure is stated, encompassing items' factor loadings in rotated component matrix.

Table 3. The Eventual Factor Solution

\begin{tabular}{lcc}
\hline \multirow{2}{*}{ Items } & \multicolumn{2}{c}{ Factors } \\
\cline { 2 - 3 } & 1 & 2 \\
\hline Item 17 & .696 & \\
Item 29 & .687 & \\
Item 30 & .685 & \\
Item 14 & .681 & \\
Item 26 & .672 & \\
Item 15 & .650 & \\
Item 13 & .642 & \\
Item 23 & .629 & \\
Item 6 & .606 & \\
Item 25 & .596 & \\
Item 18 & .574 & \\
Item 31 & .572 & \\
Item 7 & .556 & \\
Item 5 & .532
\end{tabular}




\begin{tabular}{llll} 
Item 8 & .391 & & \\
Item 12 & .380 & & \\
Item 20 & & .795 & \\
Item 3 & & .745 & \\
Item 4 & & .745 & \\
Item 33 & .743 & \\
Item 1 & .735 & \\
Item 11 & .684 & \\
Item 32 & .410 & \\
Item 22 & .369 & \\
Item 10 & & .741 \\
Item 21 & & .713 \\
Item 24 & & .687 \\
Item 28 & & .640 \\
Item 34 & & .591 \\
Item 27 & & .578 \\
Item 16 & & .475 \\
Item 2 & & .467 \\
Item 9 & & .449 \\
\hline
\end{tabular}

The three factors were depicted in the same fashion as Sullivan (2010) described due to the fact that the items were distributed into the factors in an identical way as in the original scale. They are characterized with the following names: Approach (Item 5, 6, 7, 8, 12, 13, 14, 15, 17, 18, 23, 25, 26, 29, 30 and 31), Avoidance (Item 2, 9, 10, 16, 21, 24, 27, 28 and 34) and Social Support (Item 1, 3, 4, 11, 20, 22, 32 and 33). Only Item 8 is part of a different factor - Approach - unlike the initial scale. The possible reasons for such an outcome were clarified in a detailed way by the authors in Discussion section.

\subsection{Findings of Confirmatory Factor Analysis}

CFA was performed to gauge whether three factor model of the original ACS Scale would be obtained from the data of Turkish sample. Model fit indexes used in CFA were $X^{2} / \mathrm{df}$ (Chi Square / Degree of Freedom), CFI (Comparative Fit Index), SRMR (Standardized Root Mean Square Residuals), TLI (Tucker-Lewis Index) and RMSEA (Root Mean Square Error of Approximation). They were tested based on the acceptable values specified by Tabachnick and Fidell (2007), and Schumacker and Lomax (2010). The results showed the Turkish model with 34 items was not compatible with the initial model of the ACS Scale, $\left(\chi^{2}(492)=1759.76, p<.001 ; \mathrm{GFI}=.83\right.$; $\mathrm{CFI}=.93$; $\mathrm{SRMR}=.07$; RMSEA=.08), advocating the outcomes of EFA.

Then, the Turkish ACS Scale with 33 items was tested via CFA. Model-1 and Model-2 of Turkish ACS Scale are presented in Table 4. When the modification indices in Model 1 were explored, there were noteworthy correlations between item 4 and item $20(r=.46)$, and between item 5 and 
item 6 ( $r=.17)$. An adjustment between these items was made, leading to Model-2. It can be claimed there is an enhancement in the values of the fit indexes.

Table 4. Goodness-of-Fit Indexes for Turkish ACS Scale Models

\begin{tabular}{cccccccc}
\hline & $\mathrm{df}$ & $\mathrm{X}^{2}$ & $p$ & CFI & SRMR & TLI & RMSEA \\
\hline Model-1 & 492 & 1699.25 & $<.001$ & .93 & .06 & .93 & .07 \\
Model-2 & 490 & 1449.29 & $<.001$ & .95 & .06 & .94 & .06 \\
\hline
\end{tabular}

In Figure 1, the Model-2 of the Turkish ACS Scale is demonstrated based on CFA results. 


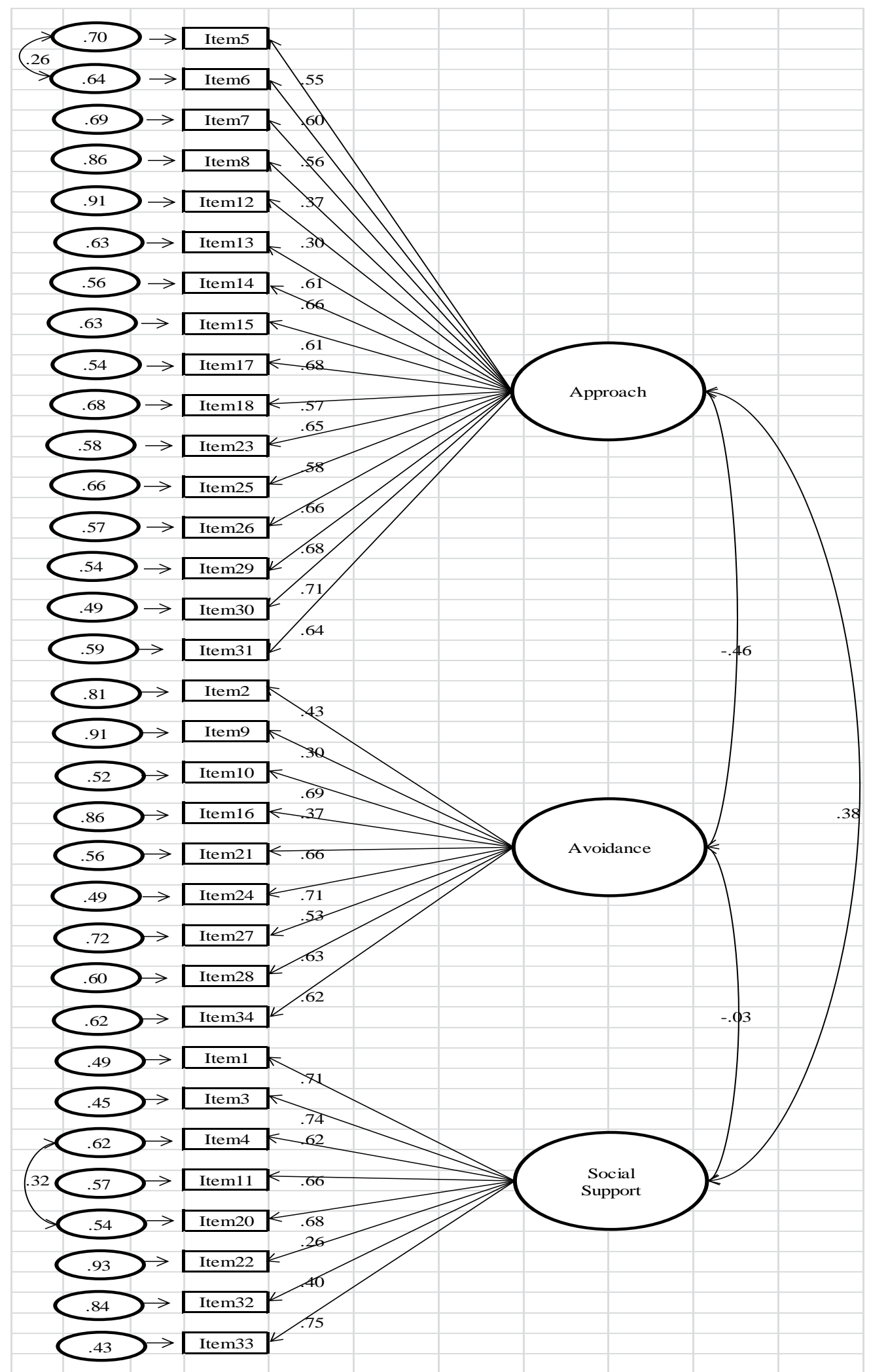

Figure1. Three Factor Model-2 of the Turkish ACS Scale 
Figure 1 consists of the items' factor loadings varying from .43 to .93 . The correlation matrix of implicit variables shows that there is a positive relation among Approach and Social Support. Yet Avoidance subscale has negative relation with these subscales. It shows the fact that the Turkish model is consonant with the theoretical structure of the initial scale.

Hence, the Turkish ACS Scale reflects a three-factor model (Approach, Avoidance and Social Support) as the original scale suggests. Yet, some items' status reveals quite differently from the initial scale. For instance, item 19 is not involved in any factor structure. Item 8 belongs to Approach subscale. The potential reasons for these findings are attributed to the fact that Turkish undergraduates cope with scholastic challenges in their educational field idiosyncratically. Thus, the following analyses were performed based on the three factor solution of 33-item Turkish ACS Scale.

\section{Findings of The Criterion Validity Analysis}

The criterion validity of 33-item Turkish ACS Scale was probed through its relationship with the Turkish versions of the Academic Self-Efficacy Scale (the ASE Scale) and Achievement Goal Orientations Scale (the AGO Scale). In Table 5, the correlations among these scales are summed up briefly. Pearson correlation analyses indicated that there are significantly positive correlations between Approach subscale and academic self-efficacy $(r=.33, p<.001)$, and Learning $(r=.42$, $p<.001)$, Performance-Approach $(r=.14, p<.001)$ subscales while it has a negative correlation with Performance-Avoidance subscale $(r=-.10, p<.05)$. Avoidance subscale has significantly positive correlations with Performance-Avoidance subscale $(r=.26, p<.001)$ unlike Learning subscale $(r=-$ $.24, p<.001)$ and the academic self-efficacy $(r=-.21, p<.001)$. Social Support subscale has significantly positive links with Learning $(r=.21, p<.001)$, Performance-Approach $(r=.17, p<.001)$ and Performance-Avoidance $(r=.12, p<.001)$ whereas it has no statistically important relation with the academic self-efficacy $(r=-.04, p>.05)$.

\section{Table 5. Correlations Among the Subscales of the Turkish ACS Scale, ASE Scale and AGO Scale}

\begin{tabular}{|c|c|c|c|c|}
\hline \multicolumn{4}{c}{} & \multicolumn{4}{c}{ The 33-Item Turkish ACS Scale } \\
\hline \multicolumn{2}{|c|}{} & Approach & Avoidance & Social Support \\
\hline \multicolumn{2}{|c|}{ The ASE Scale } & $.334^{* *}$ & $-.208^{* *}$ & -.037 \\
\hline \multirow{3}{*}{$\begin{array}{c}\text { The AGO } \\
\text { Scale }\end{array}$} & Learning & $.423^{* *}$ & $-.242^{* *}$ & $.210^{* *}$ \\
\cline { 2 - 5 } & $\begin{array}{c}\text { Performance- } \\
\text { Approach }\end{array}$ & $.145^{* *}$ & -.043 & $.174^{* *}$ \\
\cline { 2 - 5 } & $\begin{array}{c}\text { Performance- } \\
\text { Avoidance }\end{array}$ & $-.096^{*}$ & $.265^{* *}$ & $.117^{* *}$ \\
\hline${ }^{*} p<.05,{ }^{* *} p<.001$ & & & \\
\hline
\end{tabular}

\section{Results of Reliability Analysis}

Test-retest study was conducted so as to figure out if the responses given to the scale were steady or not. 40 undergraduates were randomly selected from the validity sample for this study. 
They were in the departments of Law and Management in the year of either freshmen or senior. The students were joined into the research with the interval of two weeks. Paired sampled t-test analysis showed that there is no meaningfully pivotal disparity between pre-test and post-test scores of each subscale in the 33-item Turkish ACS Scale ( $p>.05)$. Table 6 presents these results precisely.

Table 6. The Results of Paired Sampled $t$-Test of the 33-Item Turkish ACS Scale

\begin{tabular}{|c|c|c|c|c|c|c|c|c|}
\hline \multirow{2}{*}{$\begin{array}{c}\text { The 33-Item } \\
\text { Turkish ACS } \\
\text { Scale } \\
\end{array}$} & & \multirow[b]{2}{*}{$N$} & \multirow[b]{2}{*}{$\bar{X}$} & \multirow[b]{2}{*}{$S d$} & \multirow[b]{2}{*}{ SEM } & \multicolumn{3}{|c|}{$t$ Test } \\
\hline & & & & & & $t$ & $d f$ & $p$ \\
\hline \multirow{2}{*}{ Approach } & Pre-test & 40 & 59.60 & 9.65 & 1.53 & \multirow{2}{*}{-1.35} & \multirow{2}{*}{39} & \multirow{2}{*}{.18} \\
\hline & Post-test & 40 & 61.07 & 9.15 & 1.45 & & & \\
\hline \multirow{2}{*}{ Avoidance } & Pre-test & 40 & 18.45 & 5.58 & .88 & \multirow{2}{*}{.94} & \multirow{2}{*}{39} & \multirow{2}{*}{.35} \\
\hline & Post-test & 40 & 17.85 & 4.83 & .76 & & & \\
\hline \multirow{2}{*}{ Social Support } & Pre-test & 40 & 23.25 & 5.15 & .81 & \multirow{2}{*}{-1.57} & \multirow{2}{*}{39} & \multirow{2}{*}{.12} \\
\hline & Post-test & 40 & 24.40 & 5.65 & .89 & & & \\
\hline
\end{tabular}

In addition to the test-retest study, the internal consistency of the 33-item Turkish ACS Scale was analyzed. In this regard, Cronbach's alpha and split half reliability coefficients were assessed. Table 7 displays these values shortly. All coefficient values are more than .70, the approved value for the internal consistency (DeVellis, 2003).

Table 7. Cronbach's Alpha and Split Half Reliability Coefficients of Each Subscale of the 33-Item Turkish ACS Scale

\begin{tabular}{lcc}
\hline Factor & C. Alpha & S.Brown \\
\hline Approach & .89 & .83 \\
Avoidance & .78 & .73 \\
Social Support & .82 & .81 \\
\hline
\end{tabular}


Furthermore, the item-total correlation analyses of Approach, Avoidance and Social Support were made profoundly. The findings disclosed that the values of the corrected item total correlations of Approach subscale vary from .32 to .66. For Avoidance subscale, they diversify from .33 to .62. And for Social Support subscale, they alter from .31 to .70. It can be stated that all values are over .30, the recommended value for notifying that all items are pertinent to each other and are able to test the identical framework (DeVellis, 2003).

The other component of the reliability analysis was the examination of the differences of item means of the upper $27 \%$ and lower $27 \%$ groups in the subscales of the 33 -item Turkish ACS Scale. In Table 8, these results are indicated in detail. The outcomes depicted the fact that there are essential discrepancies between means of the upper $27 \%$ and lower $27 \%$ groups in Approach, Avoidance and Social Support subscales. It can be claimed that the subscales are able to differentiate the individuals in a meticulous fashion.

Table 8. Differences of Item Means of the Upper 27\% and Lower 27\% Groups in Approach, Avoidance and Social Support Subscales

\begin{tabular}{|c|c|c|c|c|c|c|c|c|}
\hline \multirow{2}{*}{$\begin{array}{c}\text { Subscales' } \\
\text { Items }\end{array}$} & \multirow[b]{2}{*}{ Groups } & \multirow[b]{2}{*}{$N$} & \multirow[b]{2}{*}{$\bar{X}$} & \multirow[b]{2}{*}{$S d$} & \multirow[b]{2}{*}{ SEM } & \multicolumn{3}{|c|}{$t$ Test } \\
\hline & & & & & & $t$ & $d f$ & $p$ \\
\hline \multirow{2}{*}{ Approach } & Lower 27\% & 136 & 49.52 & 5.38 & .46 & \multirow{2}{*}{-38.03} & \multirow{2}{*}{270} & \multirow{2}{*}{.000} \\
\hline & Upper 27\% & 136 & 71.12 & 3.86 & .33 & & & \\
\hline \multirow{2}{*}{ Avoidance } & Lower 27\% & 136 & 12.87 & 1.73 & .15 & \multirow{2}{*}{-38.63} & \multirow{2}{*}{270} & \multirow{2}{*}{.000} \\
\hline & Upper 27\% & 136 & 26.34 & 3.68 & .32 & & & \\
\hline \multirow{2}{*}{$\begin{array}{l}\text { Social } \\
\text { Support }\end{array}$} & Lower 27\% & 136 & 17.87 & 3.30 & .28 & \multirow{2}{*}{-41.04} & \multirow{2}{*}{270} & \multirow{2}{*}{.000} \\
\hline & Upper 27\% & 136 & 32.43 & 2.50 & .21 & & & \\
\hline
\end{tabular}

Moreover, the correlations among the subscales of the 33-item Turkish ACS Scale were taken into account accurately. In Table 9, the findings are outlined. Pearson correlation analyses revealed that Approach subscale has a significantly positive correlation with Social Support subscale $(r=.33, p<.001)$ while having a significanly negative link with Avoidance subscale $(r=-.33$, $p<.001)$. And there is no statistically important correlation between Avoidance and Social Support subscales $(r=.03, p>.05)$.

Table 9. Pearson Correlation Coefficients Among Approach, Avoidance and Social Support Subscales

\begin{tabular}{c|ccc}
\hline Factors & Approach & Avoidance & Social Support \\
\hline Approach & 1.00 & & \\
Avoidance & $-.326^{* *}$ & 1.00 & \\
Social Support & $.332^{* *}$ & .030 & 1.00 \\
\hline${ }^{* *} \mathrm{p}<.001$ & \multicolumn{4}{l}{}
\end{tabular}




\section{Discussion and Conclusion}

The present study had an aim at adapting the ACS Scale engendered by Sullivan (2010) to Turkish language, and exploring its validity and reliability features. The findings of EFA and CFA indicated a three factor structure - Approach, Avoidance and Social Support - with 33 items unlike the original scale composed of 34-items. Turkish undergraduates did not consider item 19 - Engaging in activities to distract you from the problem (reading, watching a movie, watching TV, listening to music- as an essential coping act taken in the face of a scholastic challenge. It reflect the fact that Turkish undergraduates dealed with academic problems in a unique fashion. They did not see such a coping behavior as an instrumental deed for handling with tedious academic challenges.

Moreover, in the study, item 8 -Wishing you were more capable of dealing with the problemappeared as the component of Approach subscale although the same item was included in Avoidance subscale in the initial scale, conducted with Hispanic undergraduates. Despite the fact that collectivistic cultural perspective emphasizing group and family concern, and interdependence exists in both Turkish and Hispanic undergraduates (Kagitcibasi, 1996, 1997; Marin and Triandis, 1985), Turkish students considered this item differently from Hispanic students. The reason behind this idea can be contributed to the fact that Turkish undergraduates wanted to display themselves positively to the present researchers instead of prefering avoidant behaviors in the face of an academic obstacle unlike Hispanic undergraduates. both of the communities indicated disparate deeds, which derived from the fact that they had different life conditions (Chun, Moos and Cronkite, 2006).

In addition, the ASE Scale and the AGO Scale were employed in order to probe the criterion validity of the 33-item Turkish ACS Scale. The results demonstrated that Approach subscale had positive correlations with academic self-efficacy, Learning and Performance-Approach subscales as opposed to its relation with Performance-Avoidance subscale. It can be claimed that the pupils adopting Approach coping strategy have a confidence in their skills of accomplishing a duty properly (Yilmaz, Gürcay and Ekici, 2007). They have a desire to obtain lots of information about the task to enhance their educational growth and/or concentrate on the hints of getting high marks to outperform the others (Akın and Cetin, 2007). Besides, Avoidance subscale had positive links with Performance-Avoidance subscale in comparison to Learning subscale and academic selfefficacy. This result can be comprehended that the ones embracing the acts of shunning from the difficult situation are more likely to abstain from other students' inhospitable views about their capacities and refrain from being emerged as an unsuccessful person (Akın and Cetin, 2007).

Furthermore, the reliability analysis which was made through Pearson correlation analysis, paired sampled t-test, Cronbach's alpha and split half coefficients, corrected item total correlation, and the differences of item means of the upper $27 \%$ and lower $27 \%$ groups in the subscales showed that the Turkish scale yields highly steady outcomes. The scores acquired from the scale display constant results as the time proceeds.

In conclusion, the 33-item Turkish ACS Scale has qualified characteristics with regard to its validity and reliability. The scale can be taken into account as a crucial tool of measurement for counselors, psychiatrists and educators to find out university students' coping strategies used 
when they feel academic stress. Especially, the identification of these handling mechanisms is essential to grasp the roots of their academic difficulties as well as failures. It facilitates the process of improving their scholastic achievement via making them be aware of whether they utilize efficacious coping systems or not in such an occasion. Early influential interventions for developing appropriate academic coping strategies are probable with this scale. To sum up, it contributes to the idea that each college student replies to academic stress in a unique way, which necessitates paying utmost attention on his/her academic coping systems.

\section{References}

Adlaf, E.M., Gliksman, L., Demers, A. ve Newton-Taylor, B. (2001). The prevalence of elevated psychological distress among Canadian undergraduates: Findings from the 1998 Canadian Campus Survey. Journal of American College Health, 50(2), 67-72. http://dx.doi.org/10.1080/07448480109596009

Akın, A. ve Çetin, B. (2007). Achievement Goal Orentations Scale: The study of validity and realiability. Eurasian Journal of Educational Research, 7(26), 1-12.

Bataineh, M.Z. (2013). Academic stress among undergraduate students: The case of education faculty at King Saud University. International Interdisciplinary Journal of Education, 2(1), 82-88. http://dx.doi.org/10.12816/0002919

Ben-Zur, H. and Zeidner, M. (2012). Appraisals, coping and affective and behavioral reactions to academic stressors. Psychology, 3(9), 713-721. http://dx.doi.org/10.4236/psych.2012.39108

Chun, C.A., Moos, R.H. \& Cronkite, R.C. (2006). Culture: A fundamental context for the stress and coping paradigm. In P.T.P. Wong \& L.C.J. Wong (Eds.), Handbook of Multicultural Perspectives on Stress and Coping (pp.29-53). USA: Springer. http://dx.doi.org/10.1007/0-387-26238-5_2

Cohen, L., Manion, L. \& Morrison, K. (2007). Research Methods in Education. (6 $6^{\text {th }}$ ed.). UK: Routledge Taylor and Francis Group.

DeVellis, R.F. (2003). Scale Development: Theory and Applications (2nd ed.). California: Sage.

Hsieh, P.H., Sullivan, J.R., Sass, D.A. ve Guerra, N.S. (2012). Undergraduate engineering students' beliefs, coping strategies, and academic performance: An evaluation of theoretical models. The Journal of Experimental Education, 80(2), 196-218. http://dx.doi.org/10.1080/00220973.2011.596853

Jerusalem, M \& Schwarzer, R. (1981). Fragebogen zur Erfassung von Selbstwirksamkeit. In R.Schwarzer (Hrsg.), Skalen zur Befindlichkeit und Persönlichkeit Forschungsbericht 5 (pp. 15-28). Berlin: Institut für Psychologie, Freie Universität Berlin.

Kagitcibasi, C. (1996). The autonomous-relational self: A new synthesis. European Psychologist, 1, 180196. http://dx.doi.org/10.1027/1016-9040.1.3.180

Kagitcibasi, C. (1997). Individualism and collectivism. In J.W. Berry, M.H. Segall \& C. Kagitcibasi (Eds.), Handbook of Cross-Cultural Psychology (pp.1-50). Boston: Allyn and Bacon.

Kuncharin, L. ve Mohamad, A.R.B. (2014). Coping strategies on academic performance among undergraduate students in Thailand. The Standard International Journals (The SIJ) Transactions on Industrial, Financial and Business Management (IFBM), 2(3), 58-61.

Lawrence, J., Ashford, K. \& Dent, P. (2006). Gender differences in coping strategies of undergraduate students and their impact on self-esteem and attainment. Active Learning in Higher Education, 7(3), 273-281. http://dx.doi.org/10.1177/1469787406069058

Lazarus, R.S. \& Folkman, S. (1984). Stress, Appraisal, and Coping. USA: Springer.

Lodico, M.G., Spaulding, D.T. \& Voegtl, K.H. (2010). Methods in Educational Research: From Theory to Practice. ( $2^{\text {nd }}$ ed.). USA: John Wiley \& Sons. 
Lowe, H. \& Cook, A. (2003). Mind the gap: Are students prepared for higher education? Journal of Further and Higher Education, 27(1), 53-76. http://dx.doi.org/10.1080/03098770305629

Marin, G. \& Triandis, H.C. (1985). Allocentrism as an important characteristic of the behavior of Latin Americans and Hispanics. In R. Diaz-Guerrero (Eds.), Cross-Cultural and National Studies in Social Psychology (pp. 85-104). Amsterdam: North Holland.

Midgley, C., Kaplan, A., Middleton, M., Maehr, M., Urdan, T., Anderman, L., Anderman, E. ve Roeser, R. (1998). The development and validation of scales assessing students' achievement goal orientations. Contemporary Educational Psychology, 23, 113-131. http://dx.doi.org/10.1006/ceps.1998.0965

Schumacker, R.E. \& Lomax, R.G. (2010). A Beginner's Guide to Structural Equation Modelling (3 ${ }^{\text {rd }}$ ed.). USA: Routledge (Taylor and Francis Group).

Struthers, C.W., Perry, R.P. ve Menec, V.H. (2000). An examination of the relationship among academic stress, coping, motiation and performance in college. Research in Higher Education, 41(5), 581592. http://dx.doi.org/10.1023/A:1007094931292

Sullivan, J.R. (2010). Preliminary psychometric data for the Academic Coping Strategies Scale. Assessment for Effective Intervention, 35(2), 114-127. http://dx.doi.org/10.1177/1534508408327609

Tabachnick, B.G. \& Fidell, L.S. (2007). Using multivariate statistics ( $5^{\text {th }}$ ed.). Boston: Pearson Education.

Thien, L.M. \& Razak, N.A. (2013). Academic coping, friendship quality, and student engagement associated with student quality of school life: A partial least square analysis. Social Indicators Research, 112(3), 679-708. http://dx.doi.org/10.1007/s11205-012-0077-x

Yılmaz, M., Gürçay, D. ve Ekici, G. (2007). Adaptation of the Academic Self-Efficacy Scale to Turkish. H.U. Journal of Education, 33, 253-259. 